\section{LAS REPRESENTACIONES DE BULTO REDONDO EN EL MEGALITISMO DEL NOROESTE}

\author{
REPRESENTATIONS OF ROUNDED \\ BULKY FIGURES IN THE MEGALITHIC \\ CULTURE OF NORTHWEST IBERIA
}

RAMON FABREGAS VALCARCE (*)

A la memoria de Cristina F.

All those moments will be lost in time, like tears in the rain... Time to die.

H. FANCHER \& D. PEOPLES, Blade Runner.

\section{RESUMEN}

Las excavaciones de la última década en megalitos gallegos han proporcionado una serie de representaciones sobre cantos rodados, decorados toscamente con incisiones o muescas. La mayoría han aparecido colocadas en una especie de atrio presente en sepulturas de corredor que se datan de la 2. ${ }^{a}$ mitad del III milenio. Algunas de estas piezas recuerdan el motivo del «tatuaje facial", común en figuras calcolíticas del Sur de la Península Ibérica.

\begin{abstract}
Although carvings or paintings on the stones of the megalithic chambers of Galicia have been known for many years, representations in the round were a rarity. The excavations undertaken in the last decade have changed somewhat that picture, yielding - among other examples- an important number of stone pebbles coarsely decorated sometimes with notches and/or incisions, the latter resembling the ufacial tattoo" motif, a widespread feature among Chalcolithic idols in the South of the Iberian Peninsula. Less numerous are the figures which show a roughly defined anthropomorphic shape though they occur beside the others in the same monuments.
\end{abstract}

(*) Area de Prehistoria. Facultade de Humanidades. Universidade de Vigo. 32004 Orense.
The larger part of these figures was found lined up in areas beside the entrance to passage-graves which are dated towards the second half of the third millenium bc. While objects with the "oculus" and "facial tattoo" motifs in the South of the Iberian Peninsula are generally regarded as representations of the so-called Mother Goddess, the morphological variety of the pieces analysed here would suggest a varied set of meanings for these.

Palabras clave: Idolos. Tatuaje facial. Atrios. Sepulcros de corredor. Calcolítico.

Key words: Idols. «Facial tattoo" motif. Courts. Passage graves. Chalcolithic.

\section{INTRODUCCION}

En un trabajo de síntesis publicado póstumamente, López Cuevillas (1959: 65) se hacía eco de la ausencia de objetos idoliformes en el mundo megalítico del Noroeste peninsular, aseveración que hasta fechas muy recientes ha conservado plenamente su validez. En efecto, a 
despecho del importante número de construcciones dolménicas que ostentaban en sus ortostatos decoración a base de grabados o, menos frecuentemente, pinturas (Shee, 1981; Rodríguez Casal, 1990), las representaciones exentas eran extraordinariamente escasas y su situación contextual estaba mal documentada: una figura antropomorfa de Paredes de Abaixo (Lugo), un betilo simple del túmulo 2 de Abelleira (Lugo) o un posible ídolo-cilindro de A Caeira (Pontevedra) (Fábregas, 1991). La rareza de esta clase de manifestaciones se constataba también en otras áreas megalíticas próximas geográficamente como Asturias, donde sólo se puede citar una pieza en el dolmen de Baradal (Jordá, 1977: 184), así como en el Norte de Portugal donde a la escultura antropomorfi recuperada en el dolmen K de Alijó (Vila Real) (Botelho 1898), sólo se podrían añadir tal vez las mal publicadas representaciones de Cova da Moura (Viana do Castelo) (Viana, 1953).

Sin embargo, el panorama descrito se ha modificado significativamente en el curso de la última década, pues la intensificación de las excavaciones efectuadas en yacimientos megalíticos del Noroeste ha permitido descubrir un ya importante elenco de figuras que en ciertos casos poseen un carácter más o menos acusadamente antropomórfico. En otro lugar (Fábregas, 1991, fig. 30) hemos efectuado una primera tentativa de ordenación de esta categoría de artefactos, clasificándolos en 7 grupos con sus correspondientes variantes. El presente trabajo se centra en el estudio pormenorizado de los grupos 1 al 3 de dicha clasificación, con mucho los más representativos numéricamente, y que muestran además una serie de particularidades en lo referente a su distribución geográfica - casi exclusivamente gallega en la actualidad-, contexto de aparición y características morfotécnicas (Fig. 1).

Hemos evitado en el encabezamiento de este trabajo el término ídolo, habitualmente empleado por los más diversos autores al referirse a esta abigarrada categoría de artefactos. Aunque ese concepto se ha aplicado generalmente con un sentido más amplio que el de representación de la divinidad, creemos más prudente no encorsetar de partida una realidad material compleja desde el punto de vista formal y todavía mal conocida por lo que al Noroeste se refiere.

T. P.. $\mathrm{n}^{\circ} 50.1993$

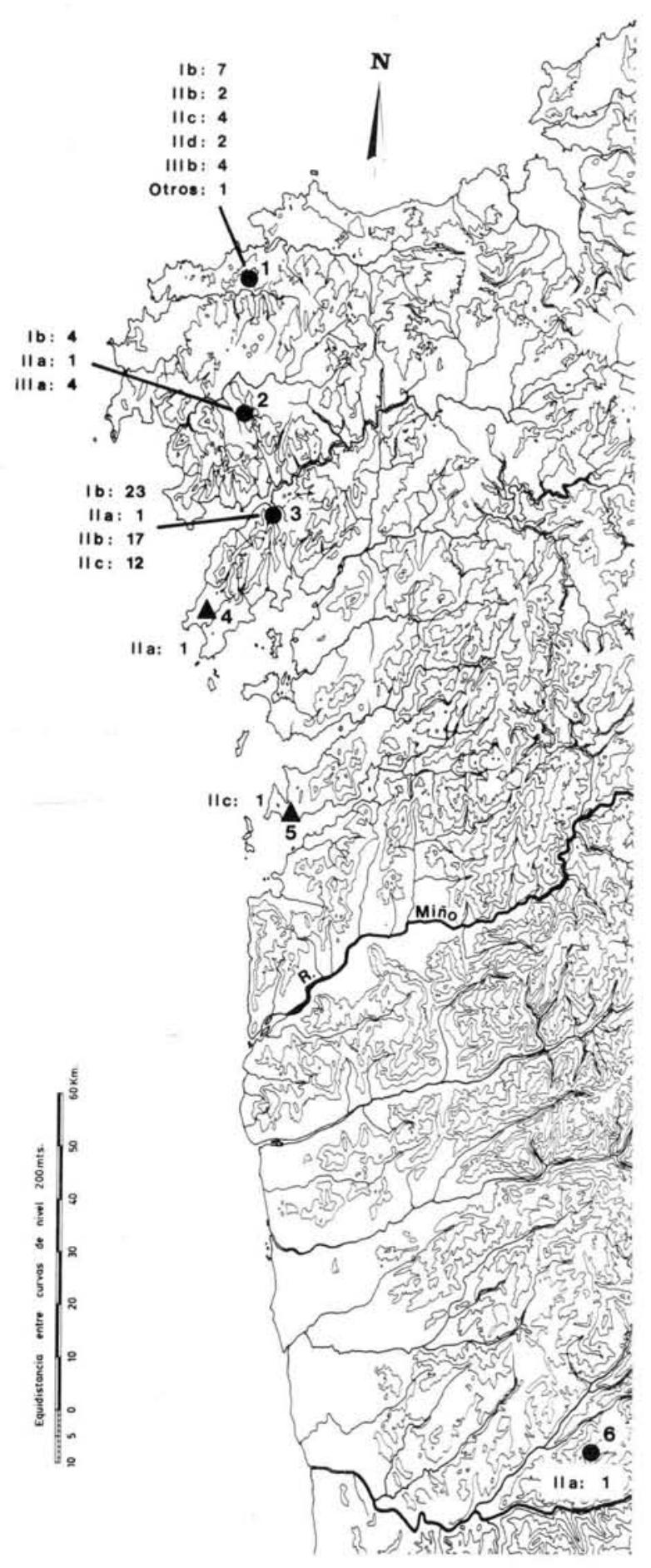

Fig. 1. Mapa de Galicia y Norte de Portugal con la distribución de las representaciones de los grupos I a III: 1. Dombate; 2. A Mina de Parxubeira; 3. Cova da Moura-Argalo; 4. Axeitos; 5. As Forcadas; 6. Touta. 


\section{ANALISIS MORFOTECNICO}

\section{Grupo I. Guijarros}

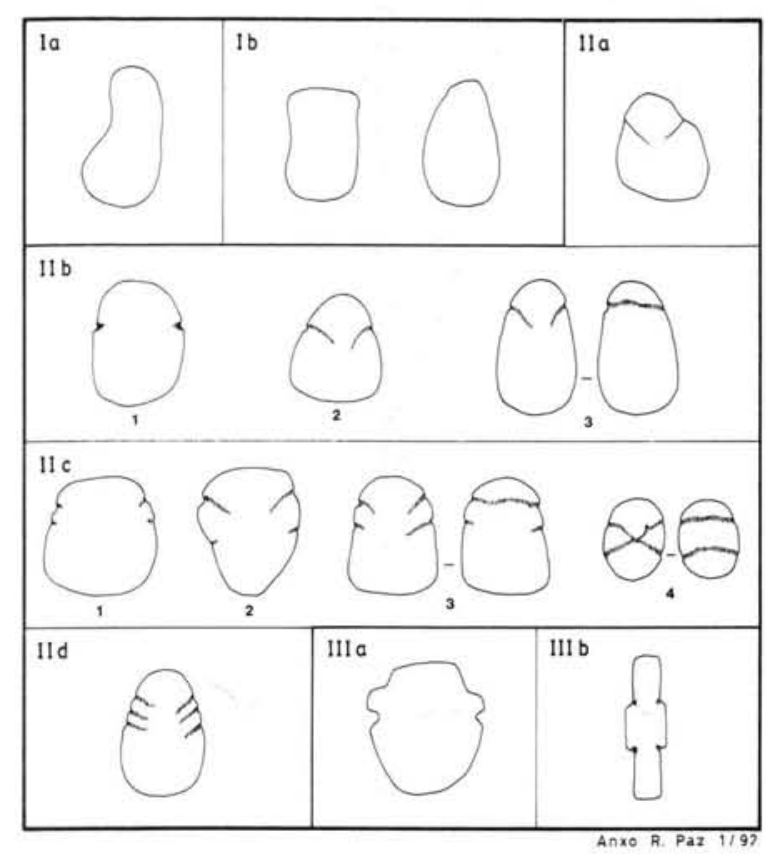

Fig. 2. Cuadro tipológico de las representaciones de bulto redondo analizadas en este trabajo.

De las tres grandes categorías que vamos a tratar a continuación (Fig. 2), es ésta la que presenta una caracterización más problemática por cuanto no consiste más que en simples cantos rodados, cuya condición artefactual viene señalada como veremos más adelante por circunstancias contextuales. Sus características morfométricas presentan no obstante ciertas regularidades: se trata de guijarros, generalmente de sección aplanada y con una silueta ovoidal, triangular o elíptica, más raramente cuadrangular. En dos ejemplares de adscripción más discutible al grupo I se documenta una forma estrangulada (tipo Ia). Las 34 piezas que podemos encuadrar con cierta seguridad en el otro tipo $(I b)$ provienen de tres sepulcros de corredor (23 de ellas de Cova da Moura -Argalo, Noia). La mayoría ( $58 \%$ ) de éstas mide entre 10 y 20 $\mathrm{cm}$. de longitud, situándose bajo el primer valor otro $27 \%$, y parecen haber sido objeto de un proceso de selección, tomando en cuenta las variables longitud y anchura, que muestran un grado apreciable de correlación $(\mathrm{r}=+0$ '79) (Fábregas, 1991, fig. 31). Aunque no dispone- mos de análisis petrográficos, la materia prima empleada consiste, al igual que sucede entre los otros dos grupos de artefactos, en rocas graníticas o metamórficas con una visible esquistosidad.

\section{Grupo II. Guijarros decorados de tipo Argalo}

Las piezas pertenecientes a este grupo presentan grandes concomitancias en cuanto a forma y proporciones con las de la categoría anterior: el soporte es en todos los casos a base de cantos rodados de granito o rocas metamórficas generalmente esquistosas y hay un cierto predominio de las siluetas elípticas (12 casos), ovoides y triangulares ( 11 y 8 casos, respectivamente).

El índice de longitud/anchura (1'7) es idéntico al del grupo precedente, mostrando así una preferencia por formas no excesivamente longilíneas. Aunque las piezas entre 10 y $20 \mathrm{~cm}$. de longitud siguen constituyendo la mayoría (59\%), en contraste con los guijarros del grupo $\mathrm{I}$, ningún ejemplar baja de los $10 \mathrm{~cm}$. de largo.

El único elemento diferenciador de las piezas del grupo II con respecto a los simples guijarros del grupo I son las someras modificaciones efectuadas sobre el soporte original, afectando a veces exclusivamente al contorno de la pieza, mientras en otras ocasiones se decora toscamente una o ambas caras. Dado que el trabajo efectuado sobre el canto rodado es tan escaso que apenas altera su forma y proporciones y estas variables son por tanto - dentro de ciertos límites- aleatorias, hemos optado por emplear como criterio discriminante de los distintos tipos los aspectos técnicos y organizativos de la decoración que presentan:

Tipo IIa (4 ejemplares en otros tantos yacimientos): se caracteriza por presentar en ambas caras una decoración a base de líneas incisas, que arrancan desde el tercio superior de la pieza y convergen hacia el centro de ésta. El número de trazos puede variar incluso entre una y otra faceta de un mismo artefacto o afectar apenas a los bordes de la pieza (mamoa da Touta). La técnica empleada consiste en hacer pasar una y otra vez un objeto agudo y ciertamente duro (una lasca de cuarzo o sílex con un filo de las características adecuadas sería más que suficiente para ejecutar la tarea) hasta 


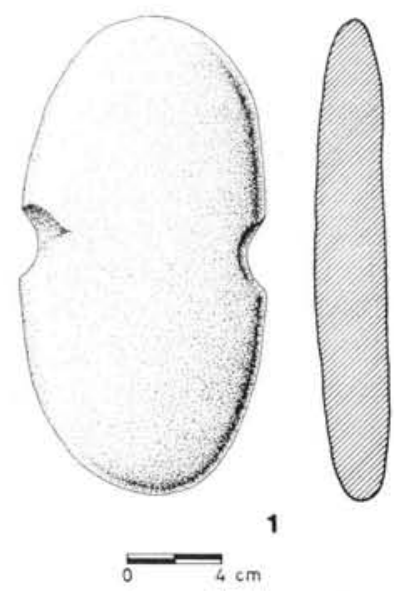

2
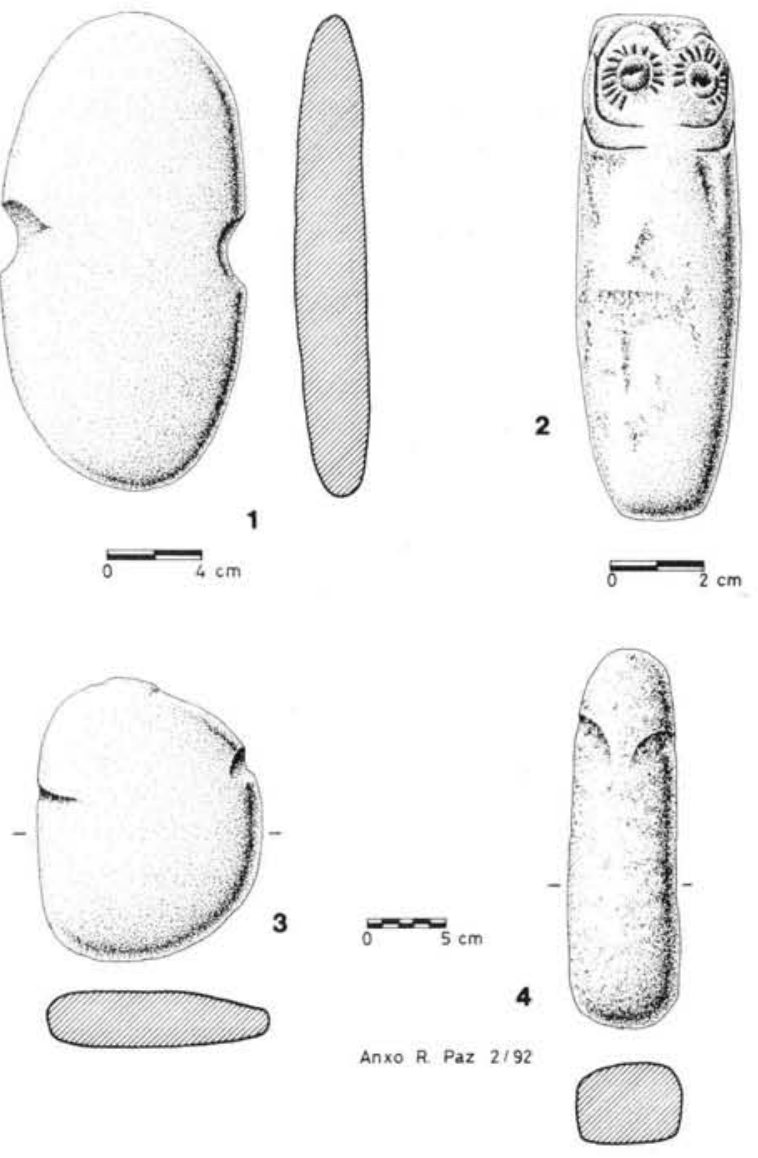

Fig. 3. 1. Idolo de tipo El Garcel (según Marqués y Ferrer, 1976); 2. Cilindro decorado de Bollullos del Condado (Huelva); 3. Guijarro del tipo IIbl ( $\mathrm{n}^{\circ} 29$ de Cova da Moura-Argalo); 4. Guijarro del tipo IIb2 ( ${ }^{\circ} 6$ de Cova da Moura-Argalo).

conseguir formar un surco de sección en « $V$ » (Lám. I, 1: detalle de la decoración de la figura no 23 de Cova da Moura -Argalo, Noia). La ejecución no es demasiado regular ni parece apreciarse en cualquiera de estas figuras una preocupación por la simetría, aún dentro de una misma cara.

En el curso de un experimento realizamos dos incisiones de las mismas características que las detectadas sobre las figuras del tipo IIa en un tiempo de unos 20 minutos, utilizando como soporte un canto rodado de granito y como instrumento grabador una lasca de cuarzo lechoso fracturada al efecto.

Tipo IIb (19 ejemplares procedentes de 2 yacimientos): es el más numeroso y muestra cierta variabilidad. Se caracteriza por poseer dos escotaduras poco profundas, situadas dentro del tercio superior del canto rodado, normalmente más estrecho o apuntado. En el subtipo IIb1 (dos ejemplares) tan sólo aparecen las mencionadas escotaduras (Fig. 3,3), mientras que en el subtipo IIb2 (dieciséis casos) éstas se prolongan dentro de las caras de la pieza en forma de leves acanaladuras que convergen hacia el centro (Fig. 3, 4), llegando a unirse eventualmente. A menudo, esos surcos están más desarrollados en una cara que en la opuesta y en un caso esta disimetría se lleva hasta el extremo de que las acanaladuras convergentes son sustituídas en una de las caras por un simple surco horizontal (subtipo IIb3).

Técnicamente - y las siguientes consideraciones son igualmente válidas para los tipos IIc y IId-, tanto las escotaduras como los surcos están conseguidos mediante repicado que se complementa las más de las veces con una mínima regularización, aunque en alguna ocasión se aprecia un pulimento propiamente dicho. Las muescas y las acanaladuras podrían haberse obtenido mediante un simple percutor de piedra con una forma algo apuntada, como se deduce de la observación de algunas piezas peor acabadas. No obstante, las huellas de impacto observables en un surco inacabado de la figura $\mathrm{n}^{\circ} 31$ de Cova da Moura (Argalo, Noia) (Lám. I, 2) plantean por su forma y hondura la posibilidad del uso de un instrumento metálico, hipótesis que desde luego tendría importantes implicaciones.

En la misma sesión experimental a la que ya aludimos más atrás, efectuamos un ensayo de elaboración de un guijarro del tipo IIb1. Con ese fin utilizamos un canto rodado de granito de sección elíptica, al cual mediante repicado se le tallaron sendas escotaduras que se continuaban sobre una cara en forma de leves acanaladuras, labor en la que se invirtieron 15 minutos, empleando como percutor un guijarro de cuarzo con una forma angulosa. Otros cinco minutos fueron necesarios para regularizar las muescas y los surcos por abrasión con un pequeño guijarro de granito.

Tipo IIc (16 ejemplares en dos yacimientos): sus integrantes se caracterizan por sus mayores dimensiones (sólo dos bajan de los $20 \mathrm{~cm}$. de longitud) y por poseer dos escotaduras en cada lado de la pieza, obtenidas mediante repicado, 


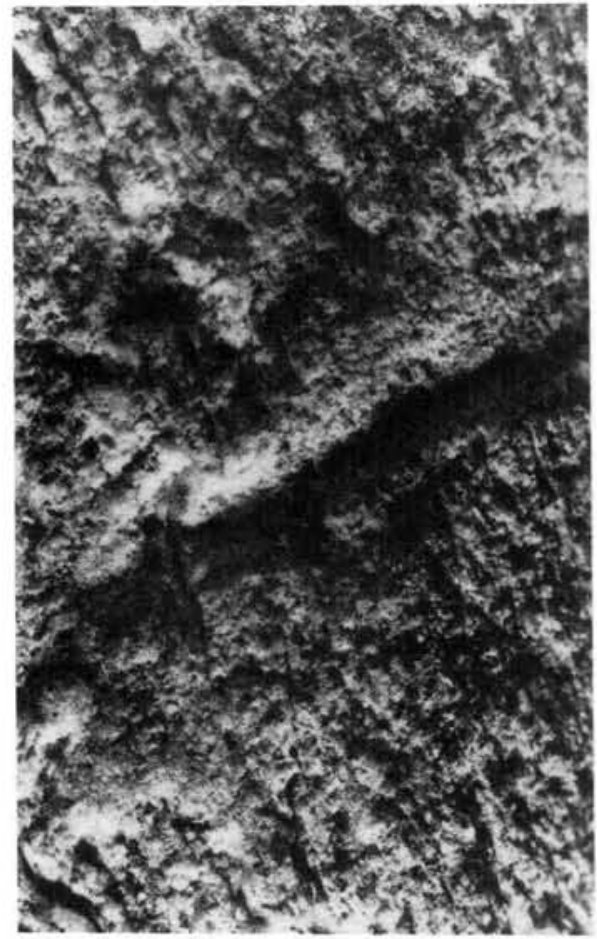

1

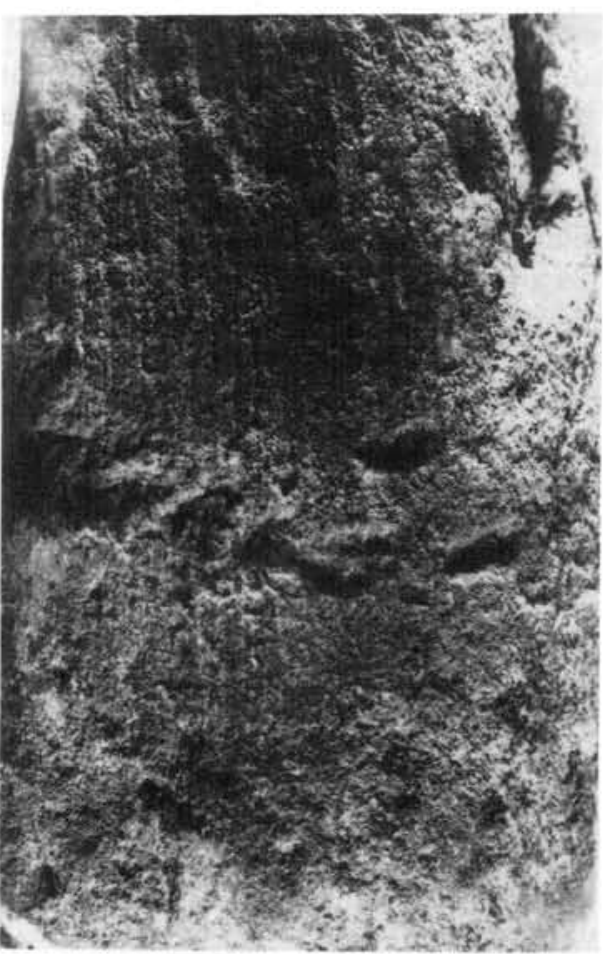

2

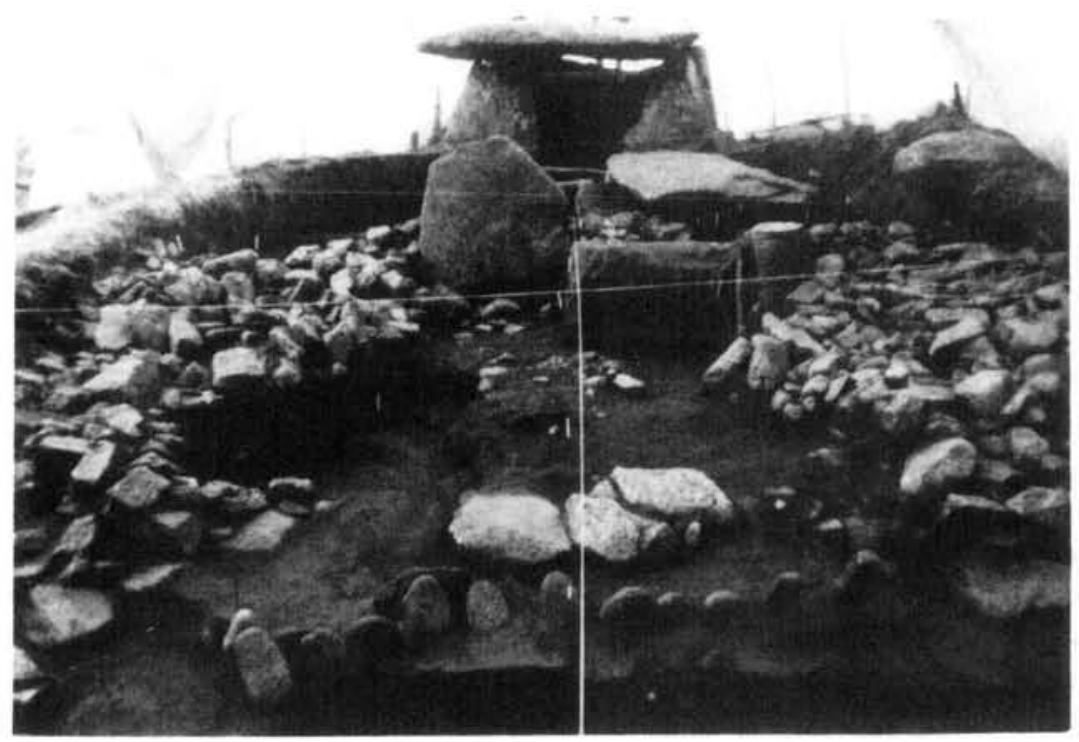

3

Lám. I. Macrofotografia de una de las acanaladuras incisas sobre un guijarro de tipo IIa ( ${ }^{\circ} 23$ de Cova da Moura-Argalo); 2) Detalle del borde de un guijarro de tipo $\operatorname{IIb} 2\left(\mathrm{n}^{\circ} 31\right.$ de Cova da Moura) mostrando una acanaladura a medio terminar. Obsérvese a la derecha de la imagen dos huellas de percusión particularmente nitídas; 3) Zona de acceso (atrio) situada frente al corredor de la sepultura de Dombate en curso de excavación. En primer término se distingue la hilera de figuras «in situ» cerrando dicha área (foto de J. M. Bello). 
que en ocasiones se combina con incisión o pulimento. Si dividimos el artefacto axialmente en dos partes aproximadamente iguales, las escotaduras mencionadas tienden a localizarse en uno de los sectores así definidos, aunque en algunos ejemplares éstas aparecen repartidas por parejas a uno y otro lado de la línea central. Con pocas excepciones, el par de escotaduras superiores (1) -o de una forma más aséptica, las más próximas a un extremo de la figura en cuestión- están más elaboradas o, en su caso, se prolongan en acanaladuras de mayor longitud. Asimismo, al igual que ya señalábamos entre los ejemplares del grupo IIb, la decoración aparece más desarrollada en una de las caras de la pieza.

El subtipo IIcI (7 casos), se caracteriza porque la decoración se circunscribe prácticamente a las escotaduras de los bordes, sin prolongarse en forma de acanaladuras sobre las caras (Fig. 4, 1). Las representaciones del subtipo IIc2 ( 7 casos) poseen largas acanaladuras convergentes en una o en ambas caras y entre éstas se cuentan ejemplares de gran tamaño (Lám. II, 1). Las escotaduras en algunas piezas de este grupo son particularmente profundas y el repicado se complementa con un pulimentado posterior. El subtipo IIc3, con sólo una pieza, sustituye en una de las caras las acanaladuras convergentes "superiores" por un simple trazo horizontal. El subtipo IIc4 (un ejemplar) constituye un desarrollo peculiar, pues en él las 4 acanaladuras llegan a contactar en el centro de una cara, formando un motivo en aspa, mientras en la opuesta se disponen en dos líneas paralelas.

Tipo IId (2 ejemplares en un yacimiento): posee tres escotaduras a cada lado, prolongándose dentro de las caras en otras tantas acanaladuras convergentes, obtenidas mediante repicado.

Más allá de la mera diferencia en cuanto a la técnica de decoración existente entre el tipo IIa y todos los demás, hay que resaltar el hecho de que en ciertas variantes de los tipos IIb o IIc, la talla de escotaduras en los laterales del

(1) Los datos suministrados por las excavaciones de Parxubeira y Dombate sugieren que la decoración, o la parte en que ésta presenta un mayor desarrollo se localiza casi siempre en la mitad superior de la pieza, cuando ésta aparece colocada verticalmente.

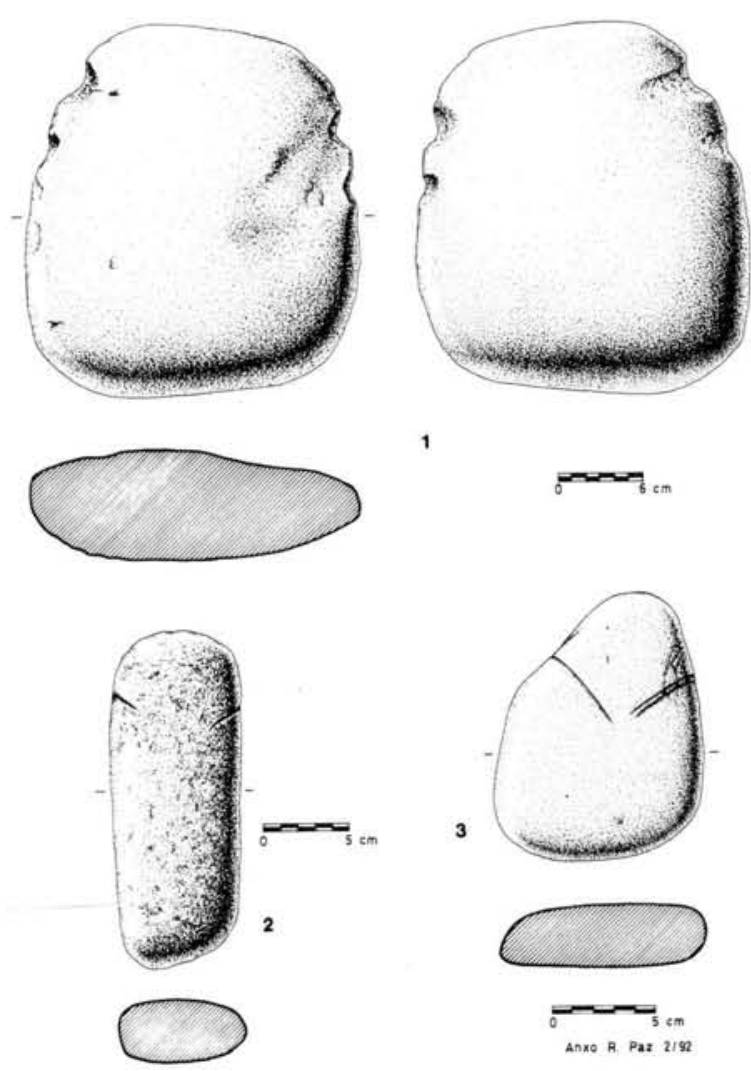

Fig. 4. 1. Guijarro del tipo IIc1 ( $\mathrm{n}^{\circ} 20$ de Cova da MouraArgalo); 2. Guijarro del tipo IIa ( $\mathrm{n}^{\circ} 23$ de Cova da Moura-Argalo); 3. Guijarro del tipo IIa (Axeitos).

guijarro parece sugerir de forma sucinta un despiece anatómico (cabeza/cuerpo; cabe$\mathrm{za}$ /tronco/extremidades inferiores), algo que ya encontramos claramente plasmado en representaciones de nuestro grupo III, las cuales aparecen en dos yacimientos junto con las anteriores.

Una amplia mayoría (30) de los guijarros decorados de tipo Argalo provienen del yacimiento epónimo (Cova da Moura, Argalo, Noia), habiéndose recuperado en el sepulcro de corredor de Dombate (Borneiro, Cabana) otros 8 y repartiéndose 3 piezas más en otras tantas sepulturas megalíticas. A los anteriores, todos ellos procedentes de contextos funerarios, habría que agregar un ejemplar del tipo IIc3, elaborado sobre un canto rodado de granito, que apareció de forma casual en un yacimiento al aire libre (As Forcadas, Cangas) (Suárez, 1990). 


\section{Grupo III. Figuras antropomórficas}

A diferencia de los dos grupos tratados anteriormente, el soporte empleado no consiste ya en cantos rodados sino en lajas de rocas graníticas o metamórficas que han sido sumariamente regularizadas en su contorno, mediante repicado $\mathrm{u}$-ocasionalmente- pulimento, complementado con escotaduras, a fin de dotar a la figura de unos rasgos antropomórficos más o menos esquemáticos. Son siempre de grandes dimensiones, pasando de los $30 \mathrm{~cm}$. en todos los casos en que se conservan completas, y hasta ahora sólo se documentan en dos yacimientos. Atendiendo a su morfología y proporciones, hemos distinguido dos variedades:

Tipo IIIa o variante Parxubeira (4 ejemplares): presenta bastantes similitudes con los subtipos IIcl y IIc2, por lo que con los datos disponibles ahora mismo, no podemos excluir que se trate de una versión local y más elaborada de éstos. No obstante, este grupo de piezas, aparecidas todas ellas en A Mina de Parxubeira, posee una serie de peculiaridades que permiten delimitarlo con claridad: grandes dimensiones (entre 38 y $49 \mathrm{~cm}$. de longitud), sección muy aplanada, elaboración sobre lajas que son repicadas y parcialmente pulidas, configurando mediante escotaduras una silueta con despiece de ciertas partes (cabeza, hombros) (Lám. II, 2). En contraste con este mayor naturalismo, no existe una pareja preocupación por decorar la superficie del objeto.

Tipo IIIb o variante Dombate (4 ejemplares, más uno dudoso, muy fragmentado): a esta variedad, documentada exclusivamente en dicha sepultura, pertenecen los ejemplares mejor terminados y aquéllos que por sus rasgos y proporciones - más canónicas- permiten apreciar un claro afán de reproducir esquemáticamente una figura antropomorfa. Para ello se recurre a modelar el contorno de la pieza mediante repicado, a la vez que con profundas escotaduras se enfatiza la separación entre cabeza, tronco y extremidades inferiores, llegando incluso en la pieza $\mathrm{n}^{\circ} 10$ a sugerir ciertos rasgos faciales (el grueso grano de la roca no autoriza mayores disquisiciones) a través de leves rehundidos (2).

(2) Queremos hacer público nuestro agradecimiento al arqueólogo responsable de la excavación de Dombate, D. José María Bello Diéguez, el cual nos facilitó el estudio de los materiales.

\section{DISTRIBUCION GEOGRAFICA Y CONTEXTO ARQUEOLOGICO}

Si examinamos la localización de las representaciones de los grupos I a III (Fig. 1) destaca inmediatamente el carácter predominantemente costero de los hallazgos, que se producen bien en la misma llanura litoral o en las primeras estribaciones de las serranías volcadas sobre ésta, a unas cotas siempre inferiores a los $400 \mathrm{~m}$. De esta pauta se separa con claridad el túmulo de Touta que se encuentra a más de $700 \mathrm{~m}$. de altitud, en la sierra de Aboboreira, situada bastante hacia el interior, si bien flanqueada por un curso fluvial tan importante como el Duero. Desde luego podría argüirse que esta distribución tan sesgada está motivada por la mayor densidad de las investigaciones efectuadas en las zonas costeras. De todos modos, aunque cabe esperar que el aumento de los trabajos arqueológicos en las comarcas centroorientales del Noroeste pueda conducir a nuevos descubrimientos de representaciones votivas, creemos que la disparidad costa-interior señalada responde probablemente a una situación real en el pasado. Ello vendría indicado no sólo por la falta de hallazgos asimilables a los grupos I a III en recientes excavaciones científicas llevadas a cabo en comarcas interiores de Galicia y Norte de Portugal, sino también por el paralelo descubrimiento de objetos cultuales de características muy distintivas en algunos de estos últimos yacimientos (Fábregas, 1991).

Centrándonos en las circunstancias contextuales de los yacimientos en los que se han hallado figuras de los grupos I a III, se aprecia de nuevo una marcada homogeneidad por cuanto cinco de un total de seis se corresponden con túmulos megalíticos. La única excepción está representada por As Forcadas que parece ser un asentamiento al aire libre, pero que tratándose de un hallazgo casual nos obliga a ser prudentes a la hora de caracterizarlo (Suárez, 1990). Del resto de los yacimientos, cuatro son sepulcros de corredor de grandes dimensiones, tres de los cuales (Dombate, Cova da Moura y Mina da Parxubeira) fueron objeto de excavaciones en fechas recientes, mientras un cuarto (Axeitos) sólo ha proporcionado un hallazgo fortuito de un guijarro del tipo IIa. El último yacimiento tumular (mamoa da Touta) se significa con relación al resto, puesto que se trata de un 

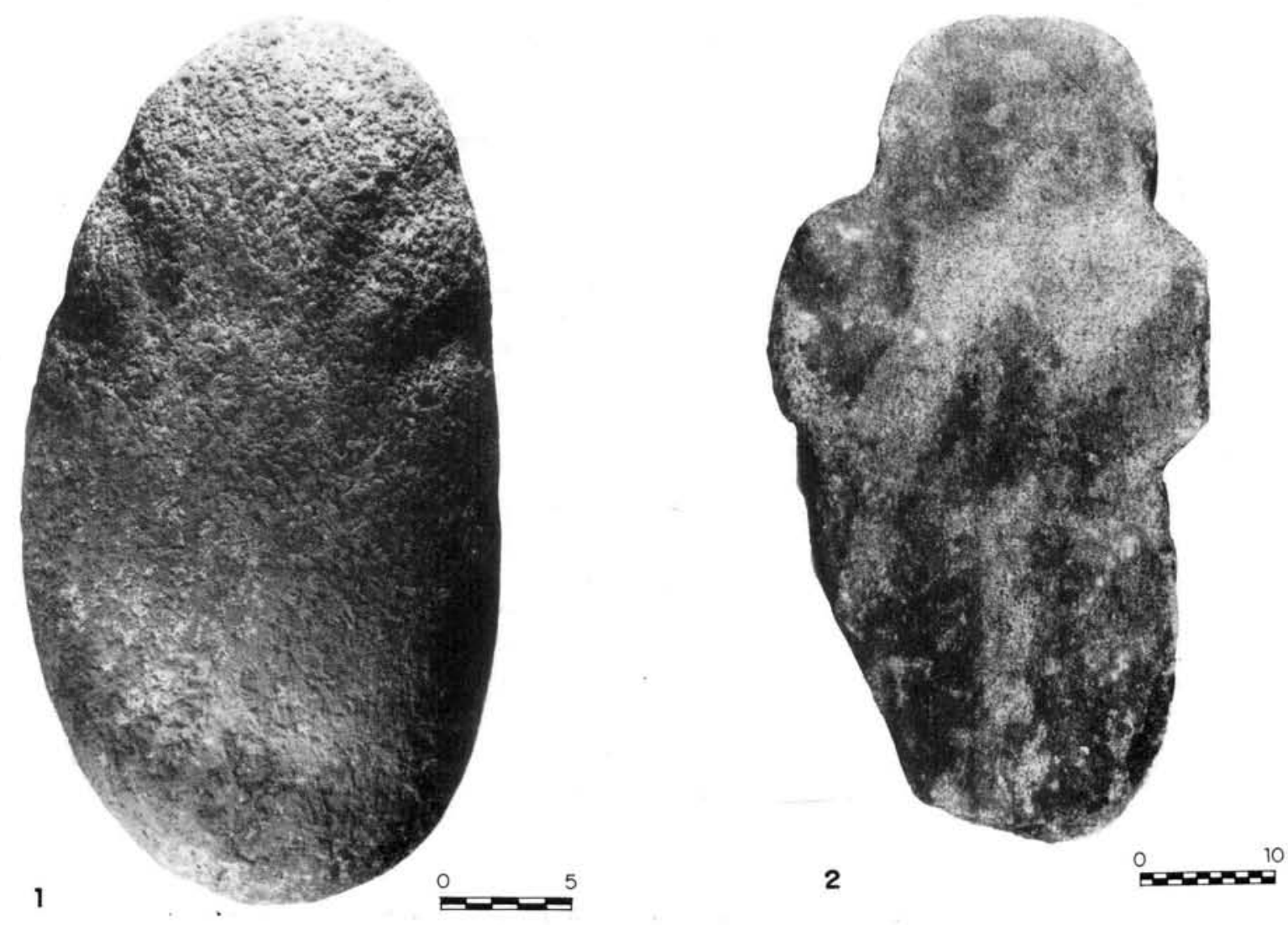

Lám. II. Guijarro del tipo IIc2 ( $\mathrm{n}^{\circ} 35$ de Cova da Moura-Argalo); 2) Figura antropomorfa de A Mina da Parxubeira.

dolmen poligonal posiblemente cerrado, habiendo aparecido un solitario guijarro de tipo IIa, muy poco elaborado, colocado intencionalmente entre los bloques de cuarzo que componían la coraza superficial cerca de la periferia del monumento, en la zanja Este (Gonçalves, 1988: 67).

Los tres sepulcros de corredor excavados se distinguen, al margen de sus proporciones, por presentar estructuras complejas de acceso a la construcción ortostática, consistentes en áreas, en ocasiones con empedrados, disponiéndose entre el final del corredor y el perímetro del túmulo. En todos los casos, las representaciones cultuales aparecieron en las zonas más exteriores de esa especie de atrios, y en los dos ejemplos mejor documentados (Dombate y Parxubeira) dichas figuras habían sido colocadas en posición vertical, alineándose transversalmente con relación al eje del corredor (Lám. I, 3).

No se aprecia una clara diferencia entre los distintos grupos y tipos de representaciones considerados por cuanto se refiere a su ubicación y éstos aparecen indistintamente mezclados. En su colocación parece seguirse, no obstante, una cierta pauta, pues casi siempre el extremo superior de la pieza coincide con la parte más apuntada o estrecha de ésta y/o la zona que presenta decoración o, como en los guijarros del tipo IIc, donde la tiene más desarrollada. Esta parte superior en las figuras antropomórficas coincide con lo que claramente parece ser la cabeza, permitiéndonos aventurar que sería éste el mismo caso en las representaciones más esquemáticas de los grupos I y II. Otro problema que se puede plantear es si estos objetos yacían enterrados originalmente o bien habrían permanecido al aire libre en el curso de la utilización del monumento, siendo cubiertos sólo cuando éste fuese clausurado. Aunque ésta es una cuestión no aclarada con base en criterios estratigráficos, consideramos posible que estaš 
piezas hubiesen estado expuestas a la intemperie durante algún tiempo, a partir de la observación de la pátina diferencial que se aprecia sobre las caras de algunas figuras. El mayor cuidado y extensión de la decoración en una de las caras (¿la dispuesta hacia el exterior?) de los guijarros de tipo Argalo podría obedecer a esa misma circunstancia.

Con relación al origen de la materia prima empleada, se puede afirmar genéricamente que se trata de rocas comunes en las respectivas zonas. Concretamente en el caso de los ejemplares de Cova da Moura, no se encuentran en los terrenos inmediatos al túmulo los cantos rodados necesarios, pero sí en el cauce de un arroyo situado a menos de un cuarto de hora de camino desde dicho monumento.

\section{DELIMITACION CRONOLOGICA Y CULTURAL}

Las informaciones disponibles en la actualidad sobre los yacimientos en que han aparecido representaciones de los grupos I a III nos permiten trazar un esbozo de su ubicación cronológica, que a grandes líneas se correspondería con la segunda mitad del III milenio, en fechas no calibradas. Esta propuesta se sustenta por una parte en las dataciones radiocarbónicas obtenidas en una estructura de tipo atrio detectada en el sepulcro de corredor de Châ de Parada 1 (Baiâo, Portugal) (3), semejante a las que han proporcionado hallazgos de objetos cultuales. Precisamente, el análisis de unos carbones recuperados a un lado del atrio de Dombate ha dado 4 fechas muy coherentes internamente (en torno al 2500 a.C.), que en nuestra opinión podrían ofrecer una datación post quem para el empleo de dicha área (4). Por otra parte, los materiales tanto líticos como cerámicos hallados en las sepulturas de Parxubeira, Cova

(3) Mientras que la construcción de este monumento puede haberse llevado a cabo poco antes de mediados del III milenio (dataciones para el nivel subyacente al túmulo: $2660 \pm 45$ y $2685 \pm 100$ a.C.), una serie de fechas $(2180 \pm 45,2230 \pm 110$ y $1990 \pm 80$ a.C. $)$ indicarian el uso de la estructura externa al corredor entre el 2300-2000 a.C., aproximadamente (Jorge, 1989: 397).

(4) La información sobre las fechas de Carbono 14 nos fue proporcionada por el excavador de ese monumento, J. M. Bello Diéguez, con quien hemos comentado además la problemática contextual de esos resultados. da Moura y Dombate indican con claridad que éstas se encuentran en plena utilización durante los momentos más avanzados del III milenio, de lo que da muestra por ejemplo la abundante aparición de campaniformes en todas ellas.

El posible asentamiento litoral de As Forcadas, con cerámicas del Calcolítico tanto campaniforme como precampaniforme (Suárez, 1986) vendría a apuntalar esa adscripción tardía para las representaciones que estamos estudiando (específicamente las del grupo II). Las cámaras poligonales simples como la de mamoa da Touta, si bien pertenecen a una tradición antigua que se remonta al IV milenio a.C., muestran una acreditada pervivencia en el conjunto del Noroeste (Fábregas, 1988). La aparición de un fragmento cerámico con decoración peinada bajo el túmulo podría señalar su construcción dentro ya del III milenio, aunque en todo caso la deposición del guijarro tipo Argalo sobre su coraza podría haberse producido con bastante posterioridad a la erección de la sepultura.

Para el establecimiento de una cronología relativa de las representaciones de bulto redondo en el megalitismo gallego no disponemos en la actualidad de datos fidedignos aunque, como veremos más adelante, cabe la posibilidad de que los guijarros del grupo I provengan de una tradición local más antigua. No obstante, la aparición conjunta de varios tipos diferentes en tres sepulturas sin que se aprecien discontinuidades de orden estratigráfico parece sugerir una coetaneidad, al menos parcial, entre todos ellos (5). A esta impresión contribuiría la capilaridad que se puede observar entre los distintos grupos y variantes: así algunos de los guijarros decorados de tipo IIc1 o IIc2 presentan notables semejanzas con las figuras del tipo IIIa, mientras que ciertas piezas del tipo IIbl prácticamente no presentan modificaciones sobre el guijarro que hace de soporte. Por último, como un ejemplo de esa continuidad entre las distintas variantes de representaciones, podríamos citar el caso de un ejemplar del tipo IIb3 hallado en Dombate, que está elaborado sobre un guijarro

(5) Sin embargo, no podemos descartar que la disposición en que encontramos estas piezas sea tan sólo el corolario final de una utilización precedente más o menos prolongada, con una cierta diacronia entre algunas de las variantes antes de que finalmente fuesen depositadas juntas. 
presentando de forma natural un aspecto claramente antropomórfico.

El encuadre cultural y cronológico de las representaciones que estamos analizando, especialmente las integrantes de nuestro grupo II, no se puede realizar adecuadamente sin valorar su vinculación con realidades presentes más allá del Noroeste peninsular, siendo las más relevantes a este respecto aquéllas procedentes del Calcolítico del Sur de la Península Ibérica. En efecto, en las regiones meridionales peninsulares encontramos algunos referentes bastante claros, tanto por lo que se refiere al soporte como a la clase de decoración que presentan los guijarros de tipo Argalo. En cuanto al primer aspecto, hay que mencionar los llamados ídolos tipo El Garcel, elaborados habitualmente-sobre guijarros de forma ovalada, a los que se les practicaron dos escotaduras en su parte media o superior (Almagro Gorbea, 1973: 27-32), dándoles así una morfología similar a la de los guijarros de tipo Argalo, en especial los de la variante IIb1 (Fig. 3, 3). Las dimensiones de los primeros (entre 2 y $7 \mathrm{~cm}$. de longitud) son sin embargo mucho menores que las de los ejemplares gallegos, aunque se conoce alguna pieza aislada de mayor tamaño, sobrepasando los $20 \mathrm{~cm}$. de largo (Marqués y Ferrer, 1976) (Fig. 3, 1). Si bien los idolos de El Garcel se encuentran prácticamente limitados al mundo millarense, algunos ejemplares rebasan ampliamente ese círculo, apareciendo en la Submeseta Sur o en el centro de Portugal: así tenemos referencias del hallazgo de tres piezas asimilables a ese tipo en la necrópolis megalítica de Lomba do Canho (Arganil, Coimbra) (Nunes, 1957) y de otras cuatro en el poblado calcolítico de Los Castillos (Las Herencias, Toledo) (Alvaro et alii, 1988).

De todos modos, la solución formal que estamos analizando (guijarro con escotaduras) es de tal sencillez que, sin descartar totalmente una génesis meridional, hay que considerar la posibilidad de que las representaciones del grupo II, más concretamente el soporte empleado, hundan sus raíces en tradiciones regionales más antiguas, tal vez neolíticas. En algunas sepulturas tumulares de Galicia y Norte de Portugal, cuya construcción data de los finales del IV milenio en fechas convencionales (v.g. Outeiro de Gregos 2 y 3 -Jorge, 1979 y 1985) se documenta la deposición intencional de simples cantos rodados, que en el caso de la mamoa 3 de Pena Mosqueira (Mogadouro, Bragança) estaban impregnados de ocre (Sanches, 1987 y 1989). En monumentos verosímilmente posteriores como el de Outeiro (Baiao, Oporto) esta costumbre se hace incluso más patente, pues aquí se depositan 32 guijarros de cuarcita en la periferia del túmulo (Faro et alii, 1988). Todavía habría que traer a colación otras referencias más antiguas y peor contrastadas, acerca de la aparición en túmulos de guijarros de procedencia alógena y que no muestran señales de utilización (v.g. Maciñeira, 1947: 136). Lejos de ser esta aniconia algo aislado y exclusivo del Noroeste, podría constituir una tradición propia del megalitismo en el Norte peninsular (ver al respecto Jordá, 1977: 195) o, incluso, en otras regiones atlánticas donde se documenta asimismo la deposición en contextos sepulcrales de simples cantos rodados (v.g. Mané-Keioned y Cöet-a-Tous en Bretaña -Le Rouzic, 1913: 79- y Ballynoe o Knowth en Irlanda - Groenman y Butler, 1976: 80; Eogan, 1986: 179-) (6).

Los datos que acabamos de mencionar sustentarían la hipótesis de que desde fecha temprana ciertos cantos rodados en contextos funerarios del Noroeste estarían dotados de un contenido simbólico cuyos alcances no podemos precisar en la actualidad. Sobre esta situación vendrían a incidir estímulos foráneos que tenderían a dotar a estos artefactos de un mayor contenido iconográfico, ya fuese completando la forma natural mediante escotaduras o trazando sobre las caras de la pieza una decoración cuyo motivo más simple y repetido consiste en un par de líneas oblicuas convergentes. Es precisamente la presencia de este tema lo que con más fuerza invoca la existencia de conexiones con el mundo calcolítico meridional. En efecto, el motivo consistente en una o varias líneas curvilíneas convergiendo desde los lados hacia el centro de la pieza, aparece con gran frecuencia en una amplia gama de ídolos calcolíticos, particularmente los cilindros decorados repartidos por las comarcas suroccidentales de la Península (Almagro, 1973: 122-142) (Figs. 3, 2 y 5,1 ), pero asimismo en ídolos-placa con

(6) También en diversos yacimientos del Sureste, entre el Neolítico y la Protohistoria más reciente, se documenta la aparición de ídolos naturales de piedra que morfológicamente recuerdan a los del tipo Garcel (Molina y Molina, 1990). 


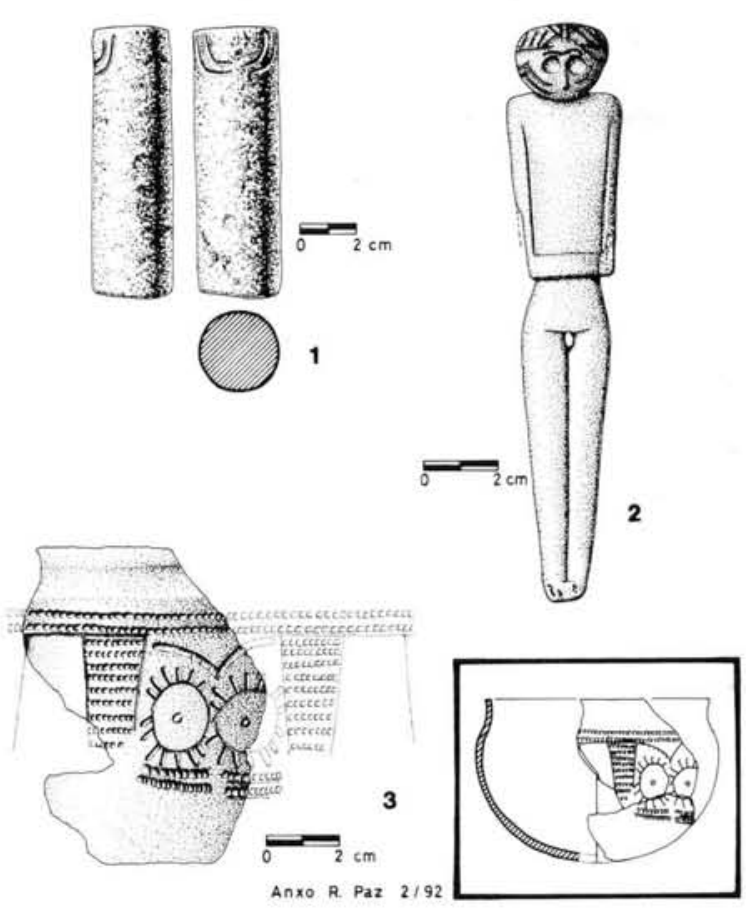

Fig. 5. 1. Cilindro decorado de la sepultura de Samarra (Sintra, Lisboa) (según Leisner, 1965); 2. Figura antropomorfa del Cerro de la Cabeza (Valencina, Sevilla) (según Fernández y Oliva, 1980); 3. Cerámica con motivo oculado del poblado de San Lourenço (Chaves, Vila Real) (según Jorge, 1986).

decoración antropomorfa o de oculados y en algunos ídolos falange (ibidem: 181-186 y 153154). La evidencia suministrada por las figuras más naturalistas parece apoyar la hipótesis de que se trata de una representación de tatuajes faciales (Fig. 5, 2), con frecuencia asociados al tema oculado (Figs. 3, 2 y 5, 3). Por otra parte, la aparición aislada en muchas figuras de la decoración de líneas convergentes (Fig. 5, 1) indicaría a nuestro entender el fuerte simbolismo contenido en esos trazos, el cual bastaría por si mismo para dotar de significado a una placa o cilindro de piedra o, como en el caso que nos ocupa, a un sencillo guijarro.

Cabe considerar al mismo tiempo que unos motivos presentes en variados contextos y cuya distribución geográfica es tan amplia, pueden haber sufrido en los distintos lugares donde aparecen reinterpretaciones o evoluciones desde el modelo y/o simbolismo originales, en función de tradiciones o dinámicas culturales propias, algo que ha sido apuntado para el occidente peninsular (Hurtado, 1978: 360) y que de hecho se produce en el caso de las figuras del megalitismo del Noroeste, las cuales (grupo II) sobre un soporte muy característico (canto rodado) muestran una versión esquematizada de la temática oculada, reducida aquí a las líneas convergentes, combinadas o no con escotaduras practicadas sobre el contorno de la pieza. Debemos resaltar que esta simplificación no es fruto del desconocimiento o ausencia de la versión canónica del motivo mencionado en esta región peninsular, pues éste hace su aparición en cerámicas de asentamientos calcolíticos como San Lourenço (Chaves, Vila Real -S. Jorge, 1986: 382) (Fig. 5, 3) y Buraco da Pala (Mirandela, Bragança) (7), así como en el túmulo 5 de Monte Pirleo (Guitiriz, Lugo) (Fuente, 1988: 245).

La cronología del motivo a base de líneas convergentes es poco precisa, por cuanto muchos de los artefactos que lo ostentan han aparecido sin un contexto estratigráfico claro. No obstante, los escasos datos disponibles señalan que su aparición o generalización se produce desde mediados del III milenio en adelante, en una etapa desarrollada del Calcolítico meridional. Así lo indican las pocas dataciones que con mayor o menor verosimilitud pueden asociarse con dichas manifestaciones: en el Cerro de la Cabeza (Valencina de la Concepción, Sevilla) tendríamos un terminus ante quem en torno al 2100 a.C. para las piezas allí recuperadas (Fernández y Oliva, 1980: 4243). La etapa precampaniforme del poblado de La Pijotilla (Badajoz) se data mediante el radiocarbono hacia el 2400 a.C. (Hurtado, 1981: 88), fecha que muy bien podría asignársele a un ídolo-cilindro de Zambujal (Torres Vedras, Extremadura portuguesa) decorado con líneas dobles convergentes, que según los excavadores pertenecería a la fase antigua del yacimiento (Sangmeister y Schubart, 1981: 268 y 282; Sangmeister et alii, 1966: 16). Otro cilindro de características semejantes fue recuperado entre el ajuar del tholos de Praia das Maçâs, para el que se dispone de una fecha radiocarbónica (1700 \pm 60 a.C.) que probablemente sirve para datar una antigua destrucción del monumento (Leisner et alii, 1969: 85-86;

(7) Información amablemente facilitada por su excavadora M. de Jesús Sanches. 
Kalb, 1981: 60). Estas indicaciones de orden cronológico no contradicen en principio las que se apuntaban más atrás para las figuras del Noroeste ni la datación que se asigna al vaso con motivo oculado de San Lourenço, hallado en un nivel correspondiente a los últimos compases del III milenio (en fechas convencionales) (S. Jorge, 1986: 388).

Resta por dilucidar la cuestión de la pervivencia de ese tema dentro del Calcolítico más tardío en el Noroeste, ya sea sobre soporte cerámico o en representaciones de bulto redondo, algo que con los datos arqueológicos en la mano no podemos afirmar ni desmentir en la actualidad. Ya aludimos a la aparición de cerámicas campaniformes en la mayoría de los yacimientos megalíticos que han suministrado figuras con decoración simbólica, pero no estamos en condiciones de precisar la cronología relativa de las primeras respecto a las segundas, al igual que sucede con el vaso oculado recuperado en el nivel más reciente del poblado de San Lourenço (S. Jorge, 1986: 388).

En tres de los sepulcros megalíticos (Parxubeira, Dombate y Cova da Moura) las representaciones de bulto redondo han aparecido concentradas en áreas muy concretas, situadas al final del corredor, abriéndose a modo de atrio entre éste y el límite exterior del túmulo. Esta localización invoca de nuevo estructuras presentes en el Calcolítico meridional, más concretamente en el Sureste. En la necrópolis de Los Millares un total de siete sepulturas han proporcionado betilos, los cuales aparecieron agrupados en pequeños recintos delimitados mediante lajas, cerca del exterior del túmulo y en las inmediaciones de la entrada al corredor, pudiendo en unos casos haber estado visibles mientras que en otros habrían sido enterrados (Leisner, 1943, láms. 85 y 14.1, 18.5, 20.1 y 22.4; Almagro y Arribas, 1963: 175; Almagro Gorbea, 1973: 66-69). En algunas sepulturas mejor conservadas se ha podido detectar la existencia de un vestíbulo (Vorhof), delimitado mediante líneas de piedras y abriéndose en forma trapezoidal desde la entrada del corredor, siendo en esa área donde se situaría el recinto que albergaba los betilos. Esa clase de estructuras, anejas al túmulo propiamente dicho y de probable finalidad cultual, han sido identificadas en otros yacimientos del Sureste y, mucho más raramente, en tholoi de la Extremadura portuguesa (Leisner, 1943: 288-289; Leisner, 1965: 172). Más al Norte, las excavaciones llevadas a cabo recientemente en el sepulcro de corredor $\mathrm{n}^{\mathrm{O}} 1$ de Moinhos do Vento, sirvieron para detectar un atrio empedrado, situado en el espacio que se abre frente al corredor del monumento (Martínez, 1983: 3). Sería en esta zona donde según las informaciones de Nunes yacía uno de los ídolos de tipo El Garcel y de donde provendrían los otros dos - hallados en las inmediaciones del monumento-, removidos de su emplazamiento original por la reciente apertura de un camino (Nunes, 1957: 196-197; Martínez, 1983: 3). Fuera de la Península Ibérica hallamos en el gran túmulo de Knowth algunos de los elementos que hemos estado comentando: algo más de una docena de cantos rodados de forma ovoide se disponían verticalmente y en fila, frente a la entrada del corredor de la sepultura Oeste (Eogan, 1986: 179 y 208). Un "ídolo-betilo» de piedra sin decoración apareció junto a la entrada al corredor de Newgrange, en el seno de una pequeña estructura (O’Kelly, 1982: 186). Por su parte, la ubicación de los posibles betilos (también de forma ovoide) en el cairn de Ballynoe es más dispersa, ya que aparecen alrededor del túmulo en sus lados NE y SE (Groenman y Butler, 1976: 80).

A la vista de las coincidencias señaladas sería tentador pensar en una dispersión desde el Sur peninsular de rituales vinculados a las áreas de entrada a las sepulturas colectivas, tal y como sugiere Eogan (1990) para los ejemplos irlandeses. Aunque en el caso del Noroeste nos encontramos ante diversos indicios de la llegada de elementos meridionales desde mediados del III milenio, creemos que el énfasis puesto en las zonas de acceso a las sepulturas, tanto aquí como en otras provincias megalíticas ibéricas o europeas, puede estar más bien relacionado con cambios de índole socioeconómica en las correspondientes comunidades, que llevan a subrayar el carácter colectivo del enterramiento tumular, incrementando a menudo la monumentalidad de las construcciones y al mismo tiempo la complejidad del ceremonial asociado a éstas. 


\section{CONCLUSIONES}

A lo largo de las páginas precedentes hemos tratado de dar una visión de las características, cronología y condiciones de aparición de una serie de representaciones que aparecen asociadas en varios yacimientos de índole funeraria del Noroeste. Al mismo tiempo hemos señalado las concomitancias de diverso orden que se observan entre estas manifestaciones en su conjunto y sus semejantes en otras áreas de la Península. Por último creemos que es necesario diseñar en la medida de lo posible las líneas de desarrollo que pueden advertirse dentro de los distintos grupos de figuras objeto de análisis.

Admitiendo como razonable, a la vista de las informaciones disponibles, que el motivo de líneas convergentes tiene su inspiración en modelos presentes en el Centro y Sur de Portugal, cabe considerar que las representaciones de tipo IIa (Figs. 4, 2 y 4, 3) constituyen la versión más fiel de aquéllos, eso si, con un mayor grado de esquematismo y empleando un soporte peculiar (canto rodado) que muy bien puede insertarse en una tradición propia del Norte peninsular. La elaboración de escotaduras en el contorno de muchos guijarros plantea la posibilidad de una influencia de las figuras de tipo El Garcel, pero en cualquier caso este modelo de decoración adquiere unos marcados visos de originalidad, a tenor de la creciente complejidad, inherente a la multiplicación de las escotaduras (tipo IIc1) y su interacción con el motivo de líneas convergentes, que de ser una simplificación del tatuaje facial puede pasar a representar las extremidades superiores. El conjunto parece apuntar hacia una reinterpretación y elaboración autóctonas de ambas temáticas en una dirección que, aún dentro del esquematismo tan caro a estas representaciones, camina hacia un todavía sumario despiece anatómico cabeza-cuerpo -insinuado por ejemplo en la transformación de las líneas oblicuas convergentes en una simple acanaladura horizontal (tipos IIb3 y IIc3)-, en línea con cierto antropomorfismo, más patente en las representaciones de los tipos IIc2 y IIc3.

Precisamente las figuras antropomórficas de Parxubeira (Lám. II, 2) pueden significar el estadio más desarrollado en ese creciente naturalismo, potenciando aquí el modelado de la pieza en un sentido más escultórico pero, en contraste con los guijarros de tipo IIc2 y IIc3, prescindiendo del contenido simbólico implícito en las líneas convergentes. La variante Dombate dentro del grupo III muestra en su marcada división cabeza-tronco-extremidades y en las proporciones longilíneas, unas características que en nuestra opinión singularizan estas figuras, aproximándolas a esculturas antropomórficas del tipo de brazos cruzados, presentes en yacimientos calcolíticos como Valencina de la Concepción (Fig. 5, 2) o La Pijotilla. Se distancian, no obstante, de estos referentes meridionales por su mayor tamaño y por la ausencia de detalle anatómico y de decoración.

Carecemos de cronologías absolutas o relativas que nos autoricen a contemplar las tendencias formales comentadas en un plano diacrónico, y ya aludíamos más atrás a los argumentos de orden morfológico y estratigráfico que abogarían por una coetaneidad, al menos parcial, de las distintas representaciones consideradas, lo cual no obsta para que los guijarros del grupo I puedan vincularse eventualmente a una tradición más antigua que las piezas del tipo Argalo, o que las figuras de caracteres más antropomórficos posiblemente se incorporen al acervo megalítico del Noroeste en un momento algo posterior.

La concentración en las comarcas costeras de una serie de representaciones cultuales con unos referentes más o menos claros en el Calcolítico meridional, no es en modo alguno fruto del azar o de unos influjos vagamente definidos, sino que se enmarca a nuestro entender en un contexto de desarrollo socioeconómico que afecta al conjunto del Noroeste, sobre todo desde mediados del III milenio, patente en un posible incremento demográfico, unido a la extensión de los asentamientos hacia zonas de menor altitud que podría deberse a cierta intensificación agrícola (S. Jorge, 1988: 86; Criado, 1989: 120; Fábregas, 1991), todo lo cual va acompañado de un aumento de los intercambios de materias primas alóctonas. En este contexto las áreas litorales, favorecidas tal vez por su mejor accesibilidad ya sea por vía terrestre o marítima y por la posibilidad de explotar una gama más 
amplia de recursos (8), presentan una dinámica específica evidenciada (Fábregas, 1990: 137), por ejemplo, en la mayor riqueza de los ajuares megalíticos costeros en puntas de flecha o grandes hojas de sílex, elaboradas con un material que habría de ser importado desde largas distancias. Si acudimos a otros apartados de la cultura material, nos encontramos con que en las comarcas atlánticas (Minho, Douro litoral, costa pontevedresa) adquiere una particular relevancia durante los últimos siglos del III milenio una variedad cerámica (genéricamente denominada de tipo Penha), cuya abigarrada decoración remite claramente a patrones estilísticos propios del Calcolítico de la Extremadura portuguesa (S. Jorge, 1986: 136-137).

A la hora de evaluar el papel que habrían jugado las representaciones estudiadas, debemos tener en cuenta que los tres yacimientos mejor estudiados y más importantes desde el punto de vista cuantitativo consistían en sepulcros de corredor y que estas piezas aparecieron no en el recinto ortostático (el panteón propiamente dicho), sino en zonas exteriores a éste. Una deducción obvia de esta circunstancia es que esas figuras tenían un carácter distinto de las ofrendas que integran el ajuar funerario sensu strictu, y su significación en el contexto del ceremonial funerario podía estar orientada tanto hacia los individuos depositados en la sepultura como hacia la sociedad en su conjunto, tanto más si estas representaciones hubiesen permanecido expuestas al aire libre. En el caso concreto de los guijarros de tipo Argalo, la presencia en ellos del motivo de líneas convergentes, asociado como hemos visto al motivo oculado, autorizaría a pensar en una extensión hacia el Noroeste de un entramado simbólico existente en el Sur de la Península, girando en torno a la denominada diosa de los ojos (9), con fuertes concomitancias mediterráneas (Hurtado, 1978; Fernández y Oliva, 1980). Debemos alertar, sin embargo, ante los peligros de extrapolar símbo-

(8) Aquí hay que recordar asentamientos calcolíticos en plena linea costera como Forcadas o Lavapés (Cangas, Pontevedra: Suárez, 1986; Peña, 1984), o el excavado recientemente en el islote de Guidoiro Areoso (Vilanova de Arousa, Pontevedra), donde además se localizó un conchero datado en el $2070 \pm 40$ bc. (Rey, 1991).

(9) Con todo, las evidencias sobre las que descansa su caracterización como divinidad no son a la hora de la verdad demasiado sólidas. los y creencias religiosas desde sociedades con una economía desarrollada y diversificada, con poblados fortificados y signos de jerarquización a otras, como las del Noroeste, con un grado de complejidad bastante menor. Por otra parte, sería un error interpretar unívocamente la temática oculada como algo vinculado exclusivamente al mundo funerario, pues tenemos documentada en el Sur su aparición en contextos domésticos, algo que también podría darse en el Noroeste.

La variabilidad que se denota en las representaciones de bulto redondo encontradas en los sepulcros de corredor de Galicia, podría indicar una multiplicidad de significados y aquí habría que señalar el inequívoco carácter masculino de ciertas esculturas antropomorfas del Sur de la Península, con las que hemos relacionado a los integrantes de nuestra variante Dombate. En cuanto a los guijarros del grupo I, carentes de cualquier clase de manipulación, cabe preguntarse si pueden equipararse a los idoliformes de los grupos II y III, o bien si representan algo distinto, a los inhumados por ejemplo, como se ha propuesto a veces para los betilos del Sureste (Leisner, 1943: 487). Estas y otras cuestiones todavía no resueltas ponen de manifiesto lo enigmático de unas manifestaciones culturales que sólo en fechas recientes han venido a nuestro conocimiento.

\section{BIBLIOGRAFIA}

Almagro, M. y Arribas, A., (1963): El poblado y la necrópolis megalíticos de Los Millares. Bibliotheca Praehistorica Hispana, III. Madrid.

Almagro Gorbea, M. J., (1973): Los idolos del Bronce I Hispano. Bibliotheca Praehistorica Hispana, XII. Madrid.

Alvaro Reguera, E. De, Municio González, L. J. y PIÑóN VARELA, F. (1988): "Informe sobre el yacimiento de "Los Castillos" (Las Herencias, Toledo): un asentamiento calcolítico en la submeseta Sur". Actas del $I^{Q}$ Congreso de Historia de Castilla-La Mancha, 2: 181-192.

Bello Diéguez, J. M. (1991): «Monumento megalítico de Dombate». Arqueoloxía-Informes, 2: 21-27.

Botel.ho, H. (1898): "Antas do concelho de Alijó». O Arqueólogo Português, 4: 180-192.

CRIADO BOADO, F. (1989): "Asentamiento megalítico y asentamiento castreño: una propuesta de síntesis". $\mathrm{Ga}$ llaecia, 11: 109-127.

Eogan, G. (1986): "Knowth and the Passage-tombs of Ireland". Thames Hudson, Londres.

- (1990): «Irish Megalithic Tombs and Iberia: Compari- 
sons and Contrasts». Probleme der Megalithgräberforschung, Berlin: 113-137.

FÁBREGAS VALCARCE, R. (1988): “Cronología y periodización del megalitismo en Galicia y Norte de Portugal». Espacio, tiempo y forma -Prehistoria-, 1: 279-291.

- (1990): «Industria lítica en el megalitismo del Noroeste peninsular: consideraciones generales". Espacio, tiempo y forma -Prehistoria - , 3: 105-141.

- (1991): «Megalitismo del Norcoste de la Península Ibérica. Tipología y secuencia de los materiales líticos». Colección Aula Abierta, 58. Madrid.

Faro, S., Cleto, J. y CARNeiro, A. L. (1988): «A escavaçâo da mamoa de Outeiro no contexto do campo arqueológico da Serra da Aboboreira". Trabalhos de Antropologia e Etnologia, 28: 251-262.

Fernández Gomez, F. y Oliva Alonso, D. (1980): «Los idolos calcolíticos del Cerro de la Cabeza (Valencina de la Concepción, Sevilla)". Madrider Mitteilungen, 21: 2044.

FUeNTE ANDRÉs, F. DE LA (1988): “El material cerámico». En R. Fábregas Valcarce y F. de la Fuente Andrés Aproximaciones a la cultura material del megalitismo gallego. Santiago: 73-154 y 223-256.

GonçAlves, A. H. B. (1988): "Escavaçâo da mamoa da Touta". Arqueologia, 17: 58-72.

GroenMAN-VAN WAATERINGE, W. y Butler, J. J. (1976): "The Ballynoe Stone Circle. Excavations by A.E. van Giffen, 1937-38». Palaeohistoria, 18: 74-104.

HURTADO, V. (1978): «Los ídolos del occidente peninsular». Habis, 9: 357-364.

- (1981): «Las figuras humanas del yacimiento de La Pijotilla (Badajoz)". Madrider Mitteilungen, 22: 78-88.

Jorda Cerda, F. (1977): Historia de Asturias, 1. Ayalga Ediciones, Vitoria.

JoRge, S. O. (1986): “Povoados da Pré-história recente da regiâo de Chaves- $V^{a} . P{ }^{a}{ }^{a}$ de Aquiarm. Instituto de Arqueologia, Oporto.

- (1988): "Reflexôes sobre a Pré-história recente do Norte de Portugaln. Trabalhos de Antropologia e Etnologia, 28: 85-112.

JoRGE, V. O. (1979): "Excavaçâo das mamoas 2 e 3 de Outeiro de Gregos". Revista de Guimarâes, 89: 251-264.

- (1985): "Novas dataçôes de radiocarbono para mamoas do concelho de Baiâo". Arqueologia, 11: 182-183.

- (1989): «Arqueologia social dos sepulcros megalíticos atlãnticos: conhecimentos e perspectivas actuais". Revista da Faculdade de Letras, 6: 365-443.

KALB, P. (1981): «Zur relativen Chronologie portugiesischer Megalithgräberm. Madrider Mitteilungen, 22: 55-77.

LE Rouzic, Z. (1913): "Carnac. Menhirs-Statues avec siqnes figuratifs et Amulettes ou Idoles des Dolmens du Morbihan". A. Dugas, Nantes.

LEISNER, G. y V. (1943): «Die Megalithgräber der Iberischen Halbinsel. Der Süden». Walter de Gruyter, Berlín.
LEISNER, V. (1965): "Die Megalithgräber der Iberischen Halbinsel. Der Westen». Walter de Gruyter, Berlín.

LeISNER, V., ZBYSZEWSKI, G. y FerReira, O. da V. (1969): "Les monuments préhistoriques de Praia das Maçâs et de Casainhos", Comunicações dos Serviços Geológicos 16, Lisboa.

LóPez Cuevillas, F. (1959): «La época megalítica en el Noroeste de la Península». Caesaraugusta, 13-14: 21-77.

MACIÑEIRA, F. (1947): “Bares, puerto hispánico de la primitiva navegación occidental». C.S.I.C., Santiago de Compostela.

MARQuÉs, I. y FerRer, J. E. (1976): “Acerca de tres ídolos de los Museos de Málagan. Zephyrus, 26-27: 479-487.

MARTÍNEZ, J. C. S. (1983): “Ideologia e práticas funerárias no megalitismo das Beiras: A sepultura periférica do quadrante NW da mamoa do dólmen $\mathrm{n}^{\circ} 1$ dos Moinhos do Vento", Revista de História Económica e Social, 11: 127.

Molina Grande, M. A. y Molina García, J. (1990): "Idolos naturales de piedra. Ampliación de su estudio". Al-Basit, 16: 109-137.

NuNES, J. de C. (1957): "Três nótulas de arqueologia préhistórica: Seixos idoliformes da Lomba do Canho, em Arganil». Revista de Guimarâes, 67: 195-198.

O'Kelly, M. J. (1982): «Newgrange: Archaeology, Art and Legend". Thames \& Hudson, Londres.

Peña Santos, A. de la (1984): "Yacimiento de Lavapés (Cangas de Morrazo). Balance de las excavaciones 19811982». Pontevedra Arqueológica, 1: 149-164.

Rey García, M. (1991): "Guidoiro Areoso (Vilanova, Pontevedra)". Arqueoloxia-Informes, 2: 29-32.

RODRÍGUEZ CASAL, A. A. (1989): La necrópolis megalítica de Parxubeira. Campañas arqueológicas de 1977 a 1984. Monografías Urxentes do Museu, 4, La Coruña.

- (1990): O megalitismo. A Primeira arquitectura monumental de Galicia. Biblioteca de Divulgación, 4. Santiago de Compostela.

SAnches, M. de J. (1987): "A mamoa 3 de Pena Mosqueira». Arqueologia, 15: 94-115.

- (1989): “Cinco datas de C14 para a Pré-história recente do Leste de Tras-os-Montes». Arqueologia, 19: 113-114.

SANGmeister, E. y SCHubart, H. (1981): "Zambujal". Philip von Zabern, Mainz.

SANGmeister, E., Schubart, H. y Trindade, L. (1966): "Escavaçôes no castro eneolítico do Zambujal -1964". Ediçâo da Câmara Municipal, Torres Vedras.

SHEE TwOHIG, E. (1981): "The megalithic art of Western Europe». Clarendon Press, Oxford.

SuÁrez Otero, X. (1986): A Edade do Bronce en Galicia: Aspectos ceramolóxicos. O Bronce Inicial, Tesis de Licenciatura inédita, Universidad de Santiago.

- (1990): «Idolo de As Forcadas». Galicia no Tempo. Catálogo de la exposición: 103.

VIANA, A. (1953): "A Cova da Moura». III Congreso Nacional de Arqueología: 481-497. 